$\begin{array}{ll}\text { Reseprints are preliminary reports that have not undergone peer review. } \\ \text { Research Square } & \begin{array}{l}\text { They should not be considered conclusive, used to inform clinical practice, } \\ \text { or referenced by the media as validated information. }\end{array}\end{array}$

\title{
Gender Differences In The Effects of Marital Status And Physical Activity On Depression Among The South Korean Elderly
}

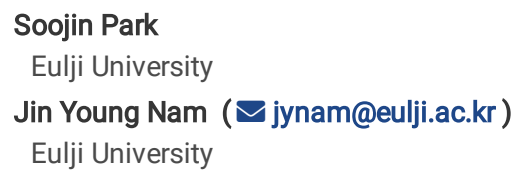




\section{Abstract}

Background: Depression in the elderly has recently drawn considerable attention as a public health issue because of its significant impact on the physical and social relationship of these individuals. We examined the association of physical activity and marital status with depression in the elderly and the related gender differences.

Methods: This study used the data of the Korea National Health and Nutrition Examination Survey (KNHANES) of 2014, 2016, and 2018. The participants were 4,134 elderly individuals aged 65 years or older. The association of physical activity and marital status with depression was analyzed using logistic regression.

Results: Out of 4,134 elderly participants, 318 had depression. Those not living with their spouse had higher prevalence of depression than those living with their spouse (women: odds ratio $[\mathrm{OR}]=1.35,95 \% \mathrm{Cl}=1.01-1.82$; men: $\mathrm{OR}=1.89,95 \% \mathrm{Cl}=1.05-3.39$ ). Moreover, spouseless elderly who engaged in physical activity was associated with depression $(\mathrm{OR}=1.65,95 \% \mathrm{Cl}=1.04-2.62)$. In the case of elderly men, the risk of depression was 2.7 times higher for those who lived alone without a spouse and engaged physical activity.

Conclusions: There was a gender difference in the association between marital status and depression, elderly men without spouses having higher risk of depression. Policymakers need to devise health programs and policies to encourage older men to engage in social activities after retirement.

\section{Introduction}

In 2015, the Global Disease Burden Study reported that depression will become a major disability affecting quality of life and physical function by 2020(1). Especially in recent years, with the growth of the elderly population, geriatric depression has become a major health concern among different ethnic groups. Geriatric depression is strongly associated with increased mortality, suicidal thoughts, risk of chronic diseases, medical cost, and reduced quality of life $(2,3)$. While common in the elderly, geriatric depression is not a symptom of normal aging (4). Depression can be caused by grief associated with aging and due to bereavement and/or loss of physical, social, or cognitive functions $(4,5)$, and is affected by several physical and social factors in combination.

The primary treatment for depression still consists in medication and psychotherapy, but lifestyle medication is a safe and cost-effective treatment (6). Regular physical activity is a major behavioral factor in the prevention and treatment of depression. Previous studies reported that elderly individuals who regularly engage in physical activities have reduced prevalence of depression compared with those who do not (7-9). This is due to the fact that physical activity involves some psychological mechanisms, such as emotional function, inducing several neurochemical changes (10).

Marital status is also a major factor associated with depression in the elderly (11). Previous studies demonstrated that bereavement or divorce negatively affect the mental health of the elderly who were left alone and causes depression, especially in men, who are at higher risk than women (5, 12,13$)$. Regardless of the differences between Eastern and Western races or cultures, studies have uniformly shown that the elderly living with their spouse have lower risk of depression (12-14).

Most previous studies focused on the relationship between either marital status or physical activity, and depression. However, as mentioned above, several factors can cause depression, making it is necessary to study the relationship between the physical and social factors associated to depression. Accordingly, the aim of the current study was to examine how the association between marital status and physical activity affects depression among South Korean elderly, and how it differs between the genders.

\section{Methods}

\section{Study participants and database information}

This study used cross-sectional raw data from the Korea National Health and Nutrition Examination Survey (KNHANES) of 2014, 2016, and 2018. The KNHANES is an epidemiological survey conducted by the Korea Centers for Disease Control and Prevention (KCDC) to monitor the health level, health behaviors, and nutrition of the South Korean population (15). The survey was approved by the Institutional Review Board (IRB) of the KCDC (approval number 2013-12EXP-03-05C for 2014, 2018-01-03-P-A for 2018). As for 2016, the KHANES was implemented without being reviewed by the IRB, according to the Bioethics Act and Enforcement Rules. All participants signed a written informed consent form of voluntary participation.

There were 23,692 total participants in the KNHANES of 2014, 2016, and 2018. In particular, the KNHANES assessed depressive symptoms, using the selfadministered Patient Health Questionnaire-9 (PHQ-9), biannually since 2014. This study initially included all participants aged 65 years or older ( $\mathrm{n}=4,871$ ). Individuals with missing data for marital status $(n=37)$, physical activity $(n=587)$, or PHQ-9 $(n=662)$ were excluded, so that eventually 4,134 elderly individuals were included in the analysis.

\section{Assessment of depression}

Depression was assessed using the PHQ-9, which is based on the Diagnostic and Statistical Manual of Mental Disorders, 4th Edition (DSM- IV) (16). The PHQ-9 is a self-administered depression screening tool for measuring major depression disorder over the previous two weeks (16). The PHQ-9 consists of nine items rated on a four-point scale from 0 (never) to 3 (nearly every day), and the scores are summed to produce the total depression severity score 
which ranges between 0 and 27 points, with 10 or more points being defined as depression (16). The Korean version of the PHQ-9 showed high internal consistency, with a Cronbach's alpha of 0.86 (17).

\section{Assessment of marital status and physical activity}

Marital status was classified by 'yes' (married) or 'no' (unmarried, divorced, widowed, or separated).

The physical activity level was evaluated by the Global Physical Activity Questionnaire (GPAQ), which was developed by the World Health Organization's (WHO) in its physical activity guidelines (18). The participants were classified into two groups: those who performed at least 75 min/week of vigorous intensity aerobic activity, at least $150 \mathrm{~min} /$ week of moderate intensity physical activity, or a combination of moderate and vigorous intensity activity (2 min of moderate intensity activity being considered equivalent to $1 \mathrm{~min}$ of vigorous intensity activity) were assigned to the 'active' group; all others were classified as 'inactive'.

\section{Covariates}

The covariates assessed in this study were gender, age (young-old: age 65-74; old-old: age $\geq 75$ years), region (city/rural), education (middle school or lower/ high school or higher), occupation (yes or no), household income (discretized based on quartile) current smoking status (yes or no), high-risk alcohol consumption (yes or no), self-rated health (good: very good or good; bad: fair, poor, or very poor), number of chronic diseases (0, 1-2, or 3 or more). Current smoking was defined as having smoked 100 or more cigarettes (five packs) in their lifetime. High-risk alcohol consumption was defined as seven or more drinks for men and five or more for women twice or more per week. Chronic diseases included those investigated in the KNHANES, namely dyslipidemia, diabetes, osteoarthritis, rheumatoid arthritis, asthma, hypertension, angina, myocardial infarction, stroke, and cancer. The types of cancer included stomach, liver, colon, breast, cervical, lung, thyroid, and other cancers. The presence of each chronic disease was assessed by asking whether the participant had been diagnosed by a physician or was currently under medication for the disease or to prevalence.

\section{Statistical analysis}

The general characteristics were analyzed by a chi-square test to assess differences by gender. The association between marital status, physical activity, and depression was analyzed with odds ratios (ORs) and 95\% confidence intervals (Cls) obtained using binary logistic regression analysis. The combined association of marital status and physical activity with depression by gender was also examined. All analyses were performed using SAS software, version 9.4 (SAS, Inc,. Cary, NC, USA), with P-values $<0.05$ considered statistically significant.

\section{Results}

Table 1 shows the prevalence of depression by demographic characteristics and gender. Out of 4,134 elderly people, 318 (7.7\%) had depression, and 3,816 (92.3\%) did not. In both men and women, marital status was significantly associated with depression ( $p=0.0025$ and $p=0.0026$, respectively), but physical activity was not $(p=0.1374$ and $p=0.4439$, respectively) [Table 1]. 
Table 1

Demographic and socioeconomic factors of study participants according to depression

\begin{tabular}{|c|c|c|c|c|c|c|c|c|c|c|c|c|c|c|c|}
\hline \multirow[t]{4}{*}{ Variable } & \multicolumn{15}{|c|}{ Depression } \\
\hline & \multicolumn{5}{|l|}{ Total } & \multicolumn{5}{|c|}{ Men } & \multicolumn{5}{|c|}{ Women } \\
\hline & \multicolumn{2}{|c|}{ Yes(N=318) } & \multicolumn{2}{|c|}{$\mathrm{No}(\mathrm{N}=3816)$} & \multirow{2}{*}{$\begin{array}{l}\mathrm{P} \\
\text { value }\end{array}$} & \multicolumn{2}{|c|}{$\operatorname{Yes}(\mathrm{N}=75)$} & \multicolumn{2}{|c|}{$\mathrm{No}(\mathrm{N}=1737)$} & \multirow{2}{*}{$\begin{array}{l}\mathrm{P} \\
\text { value }\end{array}$} & \multicolumn{2}{|c|}{ Yes(N=243) } & \multicolumn{2}{|c|}{$\mathrm{No}(\mathrm{N}=2079)$} & \multirow{2}{*}{$\begin{array}{l}\mathrm{P} \\
\text { value }\end{array}$} \\
\hline & $\mathrm{N}$ & $\%$ & $\mathrm{~N}$ & $\%$ & & $\mathrm{~N}$ & $\%$ & $\mathrm{~N}$ & $\%$ & & $\mathrm{~N}$ & $\%$ & $N$ & $\%$ & \\
\hline \multicolumn{16}{|c|}{ Marital status } \\
\hline Yes & 163 & 5.8 & 2652 & 94.2 & \multirow[t]{2}{*}{$<.0001$} & 58 & 3.6 & 1542 & 96.4 & 0.0025 & 105 & 8.6 & 1110 & 91.4 & 0.0026 \\
\hline No & 155 & 11.8 & 1164 & 88.3 & & 17 & 8.0 & 195 & 92.0 & & 138 & 12.5 & 969 & 87.5 & \\
\hline \multicolumn{16}{|c|}{ Physical activity } \\
\hline Yes & 90 & 6.3 & 1334 & 93.7 & \multirow[t]{2}{*}{0.0164} & 25 & 3.3 & 729 & 96.7 & 0.1374 & 65 & 9.7 & 605 & 90.3 & 0.4439 \\
\hline No & 228 & 8.4 & 2482 & 91.6 & & 50 & 4.7 & 1008 & 95.3 & & 178 & 10.8 & 1474 & 89.2 & \\
\hline \multicolumn{16}{|l|}{ Age } \\
\hline $65-74$ & 188 & 7.3 & 2378 & 92.7 & \multirow[t]{2}{*}{0.2589} & 41 & 3.6 & 1104 & 96.4 & 0.1180 & 96 & 10.7 & 805 & 89.3 & 0.8120 \\
\hline $75 \leq$ & 130 & 8.3 & 1438 & 91.7 & & 34 & 5.1 & 633 & 94.9 & & 147 & 10.3 & 1274 & 89.7 & \\
\hline \multicolumn{16}{|l|}{ Region } \\
\hline city & 225 & 7.4 & 2801 & 92.6 & \multirow[t]{2}{*}{0.3059} & 51 & 3.8 & 1287 & 96.2 & 0.2398 & 174 & 10.3 & 1514 & 89.7 & 0.6866 \\
\hline rural & 93 & 8.4 & 1015 & 91.6 & & 24 & 5.1 & 450 & 94.9 & & 69 & 10.9 & 565 & 89.1 & \\
\hline Education & & & & & & & & & & & & & & & \\
\hline $\begin{array}{l}\leq \text { Middle } \\
\text { school }\end{array}$ & 282 & 9.3 & 2755 & 90.7 & $<.0001$ & 24 & 3.1 & 741 & 96.9 & 0.0660 & 231 & 11.6 & 1761 & 88.4 & $<.0001$ \\
\hline $\begin{array}{l}\text { High } \\
\text { school } \leq\end{array}$ & 36 & 3.3 & 1056 & 96.7 & & 51 & 4.9 & 994 & 95.1 & & 12 & 3.7 & 315 & 96.3 & \\
\hline Missing & 5 & & & & & 2 & & & & & 3 & & & & \\
\hline Occupatic & & & & & & & & & & & & & & & \\
\hline Yes & 76 & 5.5 & 1319 & 94.5 & 0.0005 & 53 & 5.1 & 986 & 94.9 & 0.0578 & 54 & 8.7 & 569 & 91.3 & 0.2157 \\
\hline No & 242 & 8.8 & 2495 & 91.2 & & 22 & 2.9 & 750 & 97.1 & & 189 & 11.1 & 1509 & 88.9 & \\
\hline Missing & 2 & & & & & 1 & & & & & 1 & & & & \\
\hline Househol & come & & & & & & & & & & & & & & \\
\hline $1 \mathrm{Q}$ & 214 & 11.0 & 1727 & 89.0 & $<.0001$ & 47 & 6.4 & 689 & 93.6 & 0.0007 & 167 & 13.9 & 1038 & 86.1 & $<.0001$ \\
\hline $2 Q$ & 74 & 6.7 & 1030 & 93.3 & & 17 & 3.3 & 501 & 96.7 & & 57 & 9.7 & 529 & 90.3 & \\
\hline $3 Q$ & 20 & 3.2 & 596 & 96.8 & & 8 & 2.5 & 308 & 97.5 & & 12 & 4.0 & 288 & 96.0 & \\
\hline $4 Q$ & 9 & 2.0 & 441 & 98.0 & & 3 & 1.3 & 230 & 98.7 & & 6 & 2.8 & 211 & 97.2 & \\
\hline Missing & 23 & & & & & 9 & & & & & 14 & & & & \\
\hline Current sr & king & & & & & & & & & & & & & & \\
\hline Yes & 27 & 7.1 & 354 & 92.9 & 0.6975 & 15 & 4.5 & 318 & 95.5 & 0.7417 & 12 & 25.0 & 36 & 75.0 & 0.0007 \\
\hline No & 283 & 7.6 & 3421 & 92.4 & & 61 & 4.1 & 1402 & 95.9 & & 223 & 10.0 & 2019 & 90.0 & \\
\hline Missing & 49 & & & & & 17 & & & & & 32 & & & & \\
\hline High-risk & ohol cc & umptic & & & & & & & & & & & & & \\
\hline Yes & 4 & 2.5 & 154 & 97.5 & 0.0136 & 71 & 4.3 & 1584 & 95.7 & 0.3839 & 0 & 0.0 & 14 & 100.0 & 0.2019 \\
\hline No & 310 & 7.9 & 3638 & 92.2 & & 4 & 2.8 & 140 & 97.2 & & 239 & 10.4 & 2054 & 89.6 & \\
\hline Missing & 28 & & & & & 13 & & & & & 15 & & & & \\
\hline
\end{tabular}

${ }^{\dagger}$ Chronic disease included dyslipidemia, diabetes, osteoarthritis, rheumatoid arthritis, asthma, hypertension, angina, myocardial infarction, stroke, cancer (stomach, liver, colon, breast, cervical, lung, thyroid, the others cancer) 


\begin{tabular}{|c|c|c|c|c|c|c|c|c|c|c|c|c|c|c|c|}
\hline \multicolumn{16}{|c|}{ Self-rated health } \\
\hline Good & 8 & 0.9 & 902 & 99.1 & \multirow[t]{2}{*}{$<.0001$} & 3 & 0.6 & 511 & 99.4 & \multirow[t]{2}{*}{$<.0001$} & 5 & 1.3 & 391 & 98.7 & \multirow[t]{2}{*}{$<.0001$} \\
\hline Bad & 310 & 9.6 & 2913 & 90.4 & & 72 & 5.6 & 1226 & 94.5 & & 238 & 12.4 & 1687 & 87.6 & \\
\hline Missing & 1 & & & & & 0 & & & & & 1 & & & & \\
\hline \multicolumn{6}{|c|}{ Chronic diseaset } & & & & & & & & & & \\
\hline 0 & 32 & 4.7 & 648 & 95.3 & \multirow[t]{3}{*}{$<.0001$} & 6 & 1.5 & 390 & 98.5 & \multirow[t]{3}{*}{0.0011} & 26 & 9.2 & 258 & 90.9 & \multirow[t]{3}{*}{0.0636} \\
\hline $1 \sim 2$ & 173 & 7.2 & 2225 & 92.8 & & 44 & 4.2 & 1006 & 95.8 & & 129 & 9.6 & 1218 & 90.4 & \\
\hline $3+$ & 113 & 10.7 & 943 & 89.3 & & 25 & 6.8 & 341 & 93.2 & & 88 & 12.8 & 602 & 87.2 & \\
\hline
\end{tabular}

Table 2 shows the results of the binary logistic regression analysis of the association between marital status, physical activity, and depression by gender, adjusted for age, education, region, occupation, household income, current smoking status, high-risk alcohol drinking, self-rated health, and chronic diseases. Elderly men not living with their spouse had higher prevalence of depression than those living with their spouse $(\mathrm{OR}=1.89,95 \% \mathrm{Cl}=1.05-3.39)$. Similarly, elderly women not living with their spouse had a higher risk of depression than those living with their spouse $(\mathrm{OR}=1.35,95 \% \mathrm{Cl}=1.01-1.82)$. However, the association between physical activity and depression was not statistically significant in either men or women (OR $=1.20,95 \% \mathrm{Cl}=0.72-1.99$; $\mathrm{OR}=0.99,95 \% \mathrm{Cl}=0.72-1.36$ respectively). The elderly individuals with the lowest income were 3.98-fold more at risk of depression than those in the highest income level (1st quartile: $\mathrm{OR}=3.98,95 \% \mathrm{Cl}$ : 2.00-7.93; 2 nd quartile: $\mathrm{OR}=2.74,95 \% \mathrm{Cl}=1.35-5.57$ ); while elderly individuals with lower education level were 1.50 times more at risk of depression than those with higher education level $(\mathrm{OR}=1.50,95 \% \mathrm{Cl}=1.02-2.21)$. Regarding self-rated health, elderly people reporting "bad" health showed higher risk of depression than those reporting "good" health $(\mathrm{OR}=8.40,95 \% \mathrm{Cl}=4.13-17.12)$. Elderly men affected by more than three chronic diseases had a higher risk of depression than those without chronic diseases $(\mathrm{OR}=3.26,95 \% \mathrm{Cl}=1.30-8.14)[\mathrm{Table} 2]$. 
Table 2

The associations between socioeconomic factors and depression

\begin{tabular}{|c|c|c|c|c|c|c|}
\hline \multicolumn{7}{|c|}{ Depression } \\
\hline \multirow[t]{2}{*}{ Variable } & \multicolumn{2}{|c|}{ Total } & \multicolumn{2}{|l|}{ Men } & \multicolumn{2}{|c|}{ Women } \\
\hline & OR & $95 \% \mathrm{Cl}$ & $\mathrm{OR}$ & $95 \% \mathrm{Cl}$ & OR & $95 \% \mathrm{Cl}$ \\
\hline \multicolumn{7}{|c|}{ Marital status } \\
\hline Yes & 1.00 & & 1.00 & & 1.00 & \\
\hline No & 1.43 & $1.10-1.87$ & 1.89 & $1.05-3.39$ & 1.35 & $1.01-1.82$ \\
\hline \multicolumn{7}{|c|}{ Physical activity } \\
\hline Yes & 1.00 & & 1.00 & & 1.00 & \\
\hline No & 1.05 & $0.81-1.38$ & 1.20 & $0.72-1.99$ & 0.99 & $0.72-1.36$ \\
\hline \multicolumn{7}{|l|}{ Sex } \\
\hline Men & 1.00 & & 1.00 & & 1.00 & \\
\hline Women & 1.63 & $1.18-2.26$ & - & & - & \\
\hline \multicolumn{7}{|l|}{ Age } \\
\hline $65-74$ & 1.00 & & 1.00 & & 1.00 & \\
\hline $75 \leq$ & 0.80 & $0.61-1.04$ & 0.99 & $0.60-1.64$ & 0.75 & $0.55-1.03$ \\
\hline \multicolumn{7}{|l|}{ Region } \\
\hline City & 1.04 & $0.79-1.36$ & 0.87 & $0.51-1.46$ & 1.14 & $0.83-1.56$ \\
\hline Rural & 1.00 & & 1.00 & & 1.00 & \\
\hline \multicolumn{7}{|c|}{ Education } \\
\hline \multicolumn{6}{|l|}{ school } & $1.16-3.95$ \\
\hline \multicolumn{7}{|l|}{ school $\leq$} \\
\hline \multicolumn{7}{|c|}{ Occupation } \\
\hline Yes & 1.00 & & 1.00 & & 1.00 & \\
\hline No & 1.32 & $0.99-1.76$ & 1.43 & $0.83-2.45$ & 1.24 & $0.88-1.74$ \\
\hline \multicolumn{7}{|c|}{ Household income } \\
\hline $1 Q$ & 3.98 & $2.00-7.93$ & 3.27 & $0.97-11.03$ & 4.20 & $1.81-9.73$ \\
\hline $2 Q$ & 2.74 & $1.35-5.57$ & 2.12 & $0.60-7.43$ & 3.04 & $1.28-7.24$ \\
\hline $3 Q$ & 1.48 & $0.66-3.31$ & 1.83 & $0.47-7.05$ & 1.31 & $0.48-3.58$ \\
\hline $4 Q$ & 1.00 & & 1.00 & & 1.00 & \\
\hline \multicolumn{7}{|c|}{ Current smoking } \\
\hline Yes & 1.27 & $0.81-1.99$ & 0.96 & $0.53-1.74$ & 2.31 & $1.15-4.65$ \\
\hline No & 1.00 & & 1.00 & & 1.00 & \\
\hline \multicolumn{7}{|c|}{ High-risk alcohol drinking } \\
\hline Yes & 1.00 & & 1.00 & & 1.00 & \\
\hline No & 2.06 & $0.74-5.76$ & 1.53 & $0.54-4.34$ & - & - \\
\hline \multicolumn{7}{|c|}{ Self-rated health } \\
\hline Good & 1.00 & & 1.00 & & 1.00 & \\
\hline
\end{tabular}

${ }^{\dagger}$ Chronic disease included dyslipidemia, diabetes, osteoarthritis, rheumatoid arthritis, asthma, hypertension, angina, myocardial infarction, stroke, cancer (stomach, liver, colon, breast, cervical, lung, thyroid, the others cancer) 


\begin{tabular}{|c|c|c|c|c|c|c|}
\hline \multicolumn{7}{|c|}{ Depression } \\
\hline Bad & 8.40 & $4.13-17.12$ & 7.77 & $2.41-24.99$ & 8.89 & $3.62-21.86$ \\
\hline \multicolumn{7}{|c|}{ Chronic disease $^{\dagger}$} \\
\hline 0 & 1.00 & & 1.00 & & 1.00 & \\
\hline $1 \sim 2$ & 1.21 & $0.81-1.81$ & 2.49 & $1.05-5.94$ & 0.88 & $0.56-1.41$ \\
\hline $3+$ & 1.52 & $1.00-2.32$ & 3.26 & $1.30-8.14$ & 1.09 & $0.67-1.76$ \\
\hline
\end{tabular}

Figure 1 summarizes the results of the analysis of the association of the combined factors of marital status and physical activity with depression by gender. We used the combined categories of spouse and physical activity, spouse and physical inactivity, spouseless and physical activity, spouseless and physical inactivity, using spouse and physical activity as the reference group. We observed that elderly spouseless individuals performing physical activity was associated with depression $(\mathrm{OR}=1.65,95 \% \mathrm{Cl}=1.04-2.62)$ than those in the reference group. In addition, spouseless men performing physical activity had a higher risk of depression than the men in the reference group $(\mathrm{OR}=2.65,95 \% \mathrm{Cl}=1.03-6.80)$. However, combinations of marital status and physical activity were not significantly associated with depression in women. An additional table file shows this in more detail [Figure 1; see Additional file 1].

\section{Discussion}

In this study, we examined the association between marital status, physical activity, and depression in Korean elderly aged 65 or older using the KNHANES data $(2014,2016$, and 2018 surveys). With the recent worldwide increase of health concerns regarding geriatric depression, this study is expected to provide basic information for managing groups of elderly people at high risk for depression.

We found a gender-dependent association between marital status and depression, the risk of depression being higher in spouseless older men than women (men: $\mathrm{OR}=1.89,95 \% \mathrm{Cl}=1.05-3.39$; women: $\mathrm{OR}=1.35,95 \% \mathrm{Cl}=1.01-1.82$ ). This result suggests that in gender, the absence of a spouse poses a high risk of depression. Depression was also associated with education, gender, household income, self-rated health, and chronic disease. We performed regression analysis by combining the factors of marital status and physical activity and found that the risk of depression was 1.65 times higher for elderly spouseless individuals who performed physical activity. Among elderly men who performed physical activity, those living alone (including unmarried, divorced, widowed, and separated) were 2.65 times more likely to suffer from depression than the those living with their spouse.

In terms of gender, a previous study showed that women aged 60 or older are at higher risk of depression than older men (19). The risk of depression increases in adulthood owing to gender-role stereotypes and inequalities between women and men $(2,14)$. The specific factors associated with depression may vary due to the cultural differences among countries. Confucian cultures can have a significant impact on depression mediated by the inequality in gender roles $(14,20)$. Among the demographic characteristics, economic factors and education levels also affect depression, with low household income and education levels increasing the risk of depression (21). In general, highly educated people can alleviate depression by enjoying more opportunities to participate in various social activities, thanks to their high awareness and wide interests (21).

In present study, older individuals with poor self-rated health and those with chronic diseases had high risk of depression. The risk of depression was associated in the elderly with poor self-rated health in both genders (men: $\mathrm{OR}=7.77,95 \% \mathrm{Cl}=2.41-24.99 ;$ women: $\mathrm{OR}=8.89,95 \% \mathrm{Cl}=3.62-21.86$ ). Furthermore, elderly individuals with more than three chronic diseases were 1.52 times more at the risk of depression than those without chronic diseases. Previous studies reported that self-rated health was a major predictor of depression in the elderly (22).

Physical activity, age, occupation, current smoking status, or high-risk alcohol drinking were not associated with depression in this study. The differences with the results of previous studies might depend on the number of participants and the target age group. We analyzed 4,134 participants from three years of data, among whom only $318(7.7 \%)$ had depression.

We found that marital status affected geriatric depression more than physical activity. The analysis of the combined association between marital status and physical activity with depression showed that elderly individuals living alone and performing physical activity had a 1.65-fold higher risk of depression than the reference group (Figure 1). Specifically, older physically active men without spouse had a 2.65-fold higher risk of depression than the reference group. This result is in agreement with those of previous studies showing that older spouseless men are at higher risk of depression than spouseless older women $(12,13)$. It is well known that older adults who feel loneliness or live alone (unmarried, divorced, widowed, or separated) are more prone to depression than those who do not (11). Social isolation and loneliness also limit physical activity and cause prolonged sedentary behavior (23). According to Jang et al.'s study showed that husbands receive more physical and emotional support from their wives (14). Furthermore, as is typical in patriarchal Oriental family cultures, Korean older men tend to rely more on their spouses after retirement, so they suffer more grief after they separate from their spouses (14). Therefore, the awareness of fixed gender roles should be improved in Korea, and it seems necessary to enable the elderly to actively participate in social activities in order to ease the burden of depression among older adults (5).

Although this study found no association between physical activity and depression, many previous ones reported that regular physical activities such as aerobic activity and flexibility exercises were effective lifestyle interventions to prevent depression in the elderly $(6,7,24)$. This effect is due to the fact that physical activity enables social support, such as communication with people and enhanced friendships, along with the promotion of psychological 
stability and health conditions (6). Wen et al's study indicated that low levels of exercise, defined as 15 minutes per day or 90 minutes per week at moderate intensity, were beneficial in preventing disease (25). Therefore, exercise intensity and duration for this age groups should be continuously studied to further support policies to prevent depression and all-cause mortality (8).

The present study had several limitations. First, three years of data were collected, but the sample size was relatively small. Out of 4,134 people analyzed, only 318 (7.7\%) had depression, and some variables could not be analyzed because, for example, there were no elderly women with high-risk alcohol consumption among the participants. Therefore, it is necessary to construe the results carefully. Second, this is a cross-sectional study, so that we cannot prove any causal effect of marital status or physical activity on depression. Third, standards for physical activity for the elderly with world-proven reliability are not available and could not be applied. Fourth, the KNHANES is a self-reporting survey of the general population in South Korea, based on subjective answers by the participants and on limited quantitative measurements.

Despite these limitations, the study has several strengths. First, the KNHANES is a relatively large national community-based survey. Second, this study found that elderly people without spouse had a higher risk of depression, with differences between the genders. Third, since the chosen independent variables have a simple intuitive meaning, the results can be used as basic data to encourage social participation in the prevention of depression among elderly.

\section{Conclusions}

In summary, there were gender differences in the combined effects of marital status and physical activity on depression. The elderly should practice physical activity to prevent depression, and strive for their positive mental health by engaging in social activity after retirement. Therefore, policymakers need to come up with health programs and policies to encourage older men to engage in social activities after retirement.

\section{List Of Abbreviations}

KNHANES : Korea National Health and Nutrition Examination Survey

KCDC: Korea Centers for Disease Control and Prevention

IRB: Institutional Review Board

PHQ-9: Patient Health Questionnaire-9

DSM- IV: Diagnostic and Statistical Manual of Mental Disorders, 4th Edition

GPAQ: Global Physical Activity Questionnaire

WHO: World Health Organization

OR: Odds ratios

Cl: Confidence intervals

PA: Physical activity

\section{Declarations}

Ethics approval and consent to participate

The survey was approved by the Institutional Review Board (IRB) of the KCDC (approval number 2013-12EXP-03-05C for 2014, 2018-01-03-P-A for 2018). As for 2016, the KHANES was implemented without being reviewed by the IRB, according to the Bioethics Act and Enforcement Rules. All participants signed a written informed consent form of voluntary participation. All methods were performed in accordance with the relevant guidelines and regulations.

\section{Consent for publication}

Not applicable.

\section{Availability of data and materials}

The datasets generated and/or analyzed during the current study are available in the KNHANES repository, [https://knhanes.cdc.go.kr/knhanes/eng/index.do].

\section{Competing interests}

The authors declare that they have no competing interests

Funding 
This research did not receive any specific grant from funding agencies in the public, commercial, or not-for-profit sectors.

Authors'contributions

Conceptualization, J.-Y.N.; formal analysis, S.-J.P., and writing-original draft preparation, S.-J.P.; writing-review and editing, J.-Y.N. All authors have read and agreed to the published version of the manuscript.

Acknowledgements

Not applicable

\section{References}

1. James SL, Abate D, Abate KH, Abay SM, Abbafati C, Abbasi N, et al. Global, regional, and national incidence, prevalence, and years lived with disability for 354 diseases and injuries for 195 countries and territories, 1990-2017: a systematic analysis for the Global Burden of Disease Study 2017. The Lancet. 2018;392(10159):1789-858.

2. Padayachey U, Ramlall S, Chipps J. Depression in older adults: prevalence and risk factors in a primary health care sample. South African family practice. 2017;59(2):61-6.

3. Zhang Y, Chen Y, Ma L. Depression and cardiovascular disease in elderly: current understanding. Journal of Clinical Neuroscience. 2018;47:1-5.

4. Jaul E, Barron J. Age-related diseases and clinical and public health implications for the 85 years old and over population. Frontiers in public health. 2017;5:335.

5. Won HJ, Song SA. Effect of Spousal Bereavement on Depression of the Elderly: Analysis of the Impact of Traditional Gender Norms through Gender Comparison. Health and Social Welfare Review. 2019; 39(4):145-72. http://dx.doi.org/10.15709/hswr.2019.39.4.145

6. Roh HW, Hong CH, Lee Y, Oh BH, Lee KS, Chang KJ, et al. Participation in physical, social, and religious activity and risk of depression in the elderly: a community-based three-year longitudinal study in Korea. PloS one. 2015;10(7):e0132838.

7. Byeon H. Relationship between physical activity level and depression of elderly people living alone. International journal of environmental research and public health. 2019;16(20):4051.

8. Chang Y-C, Lu M-C, Hu I-H, Wu W-Cl, Hu SC. Effects of different amounts of exercise on preventing depressive symptoms in community-dwelling older adults: a prospective cohort study in Taiwan. BMJ open. 2017;7(4):e014256.

9. Kim B. Factors Influencing Depressive Symptoms in the Elderly: Using the 7th Korea National Health and Nutrition Examination Survey (KNHANES VII1). Journal of Health Informatics and Statistics. 2020;45(2):165-72.

10. Erickson KI, Gildengers AG, Butters MA. Physical activity and brain plasticity in late adulthood. Dialogues in clinical neuroscience. 2013;15(1):99.

11. Domènech-Abella J, Lara E, Rubio-Valera M, Olaya B, Moneta MV, Rico-Uribe LA, et al. Loneliness and depression in the elderly: the role of social network. Social psychiatry and psychiatric epidemiology. 2017;52(4):381-90.

12. Bulloch AG, Williams JV, Lavorato DH, Patten SB. The depression and marital status relationship is modified by both age and gender. Journal of affective disorders. 2017;223:65-8.

13. Jadhav A, Weir D. Widowhood and depression in a cross-national perspective: Evidence from the United States, Europe, Korea, and China. The Journals of Gerontology: Series B. 2018;73(8):e143-e53.

14. Jang S-N, Kawachi I, Chang J, Boo K, Shin H-G, Lee H, et al. Marital status, gender, and depression: analysis of the baseline survey of the Korean Longitudinal Study of Ageing (KLoSA). Social science \& medicine. 2009;69(11):1608-15.

15. Kweon S, Kim Y, Jang M-j, Kim Y, Kim K, Choi S, et al. Data resource profile: the Korea national health and nutrition examination survey (KNHANES). International journal of epidemiology. 2014;43(1):69-77.

16. Kroenke K, Spitzer RL, Williams JB. The PHQ-9: validity of a brief depression severity measure. Journal of general internal medicine. 2001;16(9):60613.

17. Han C, Jo SA, Kwak J-H, Pae C-U, Steffens D, Jo I, et al. Validation of the Patient Health Questionnaire-9 Korean version in the elderly population: the Ansan Geriatric study. Comprehensive psychiatry. 2008;49(2):218-23.

18. World Health Organization. Global physical activity questionnaire (GPAQ) analysis guide. Geneva; 2012.

19. Girgus JS, Yang K, Ferri CV. The gender difference in depression: are elderly women at greater risk for depression than elderly men? Geriatrics. 2017;2(4):35.

20. Girgus JS, Yang K. Gender and depression. Current Opinion in Psychology. 2015;4:53-60.

21. Xue Y, Lu J, Zheng X, Zhang J, Lin H, Qin Z, et al. The relationship between socioeconomic status and depression among the older adults: The mediating role of health promoting lifestyle. Journal of Affective Disorders. 2021;285:22-8.

22. Bae SM. Factors associated with depressive symptoms among elderly Koreans: the role of health status, work ability, financial problems, living alone, and family relationships. Psychogeriatrics. 2020;20(3):304-9.

23. Schrempft S, Jackowska M, Hamer M, Steptoe A. Associations between social isolation, loneliness, and objective physical activity in older men and women. BMC public health. 2019;19(1):1-10. 
24. Park JE, Lee JY, Kim BS, Kim KW, Chae SH, Cho MJ. Above-moderate physical activity reduces both incident and persistent late-life depression in rural Koreans. International journal of geriatric psychiatry. 2015;30(7):766-75.

25. Wen CP, Wai JPM, Tsai MK, Yang YC, Cheng TYD, Lee M-C, et al. Minimum amount of physical activity for reduced mortality and extended life expectancy: a prospective cohort study. The lancet. 2011;378(9798):1244-53.

\section{Figures}

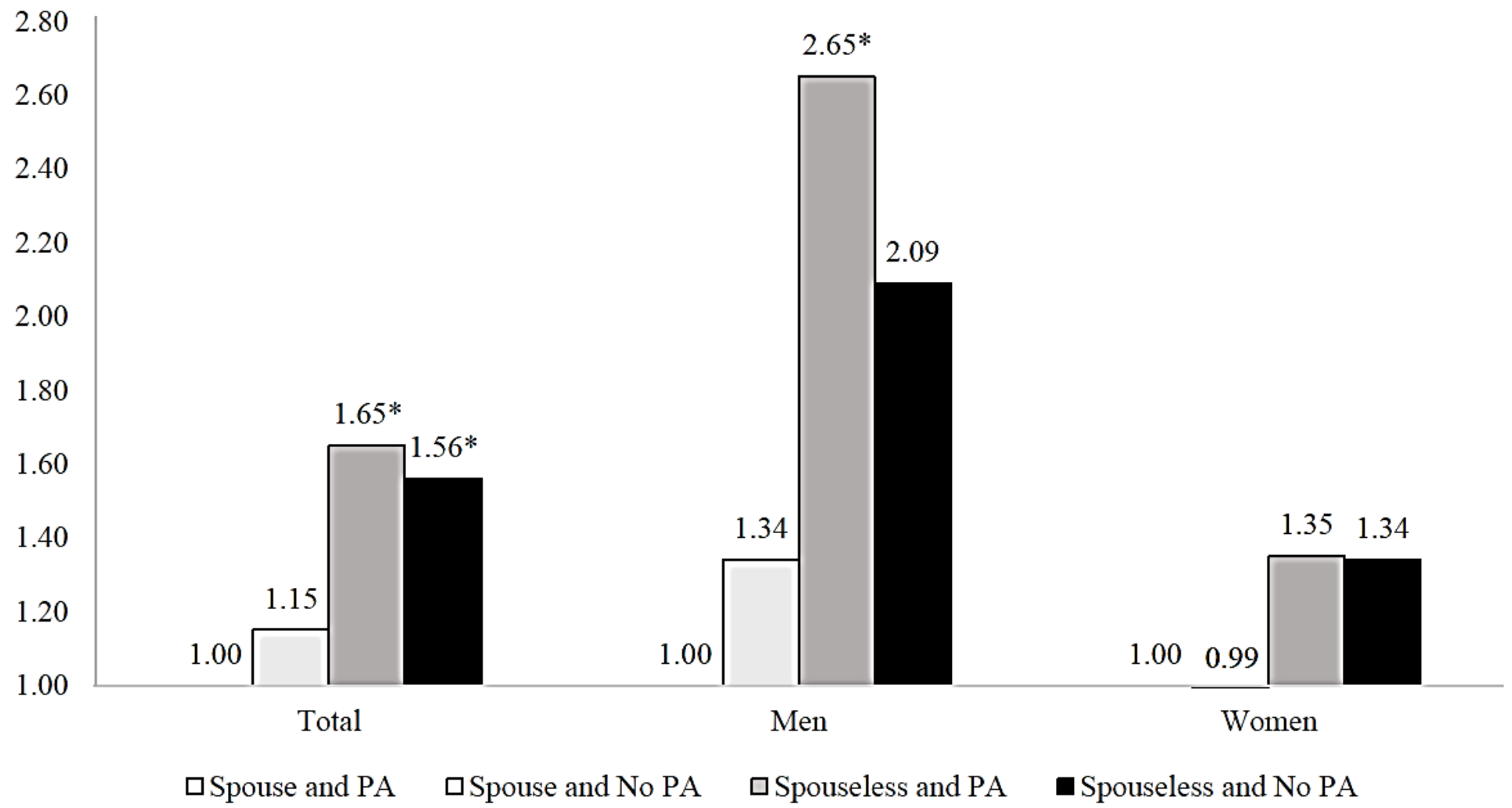

Figure 1

The associations between marital status and physical activity and depression by sex PA= Physical activity; Adjusted for age, education, region, occupation, household income, current smoking status, high-risk alcohol drinking, self-rated health, and chronic disease. * $p>0.05$

\section{Supplementary Files}

This is a list of supplementary files associated with this preprint. Click to download.

- Additionalfile1.docx 